\title{
Multirotor Heavy Lift Drone
}

\author{
Fausto Freire Carrera ${ }^{1,2 *}$, Pablo Tamayo $^{2}$, Olga Chadrina $^{1}$, and Sergei Kharlamov $^{2}$ \\ ${ }^{1}$ Faculty of Engineering Sciences and Industries, Mechatronics, UTE University, Rumipamba y Bourgeois, Ecuador \\ ${ }^{2}$ Robotics Laboratory, Central University of Ecuador, EC-170129, Av. América, Ecuador
}

\begin{abstract}
This article begins by analysing the fields of application of cargo drones at an international level, to then determine the most used configurations and with the best performance to lift important loads, from which a coaxial octocopter drone with X8 configuration was designed and built, with a payload capacity of up to $20 \mathrm{~kg}$ and a flight range of 45 minutes. The relevance to build in Ecuador of this type of drones was also analysed and thus minimize technological dependence. The results showed that it starts with $31 \%$ of national components and that by executing activities aimed at reducing dependency, in a period of 5 years it can reach $63.8 \%$ of national components for the construction of drones of these characteristic.
\end{abstract}

\section{Introduction}

According to J'son \& Partners Consulting [1] the world drone market size in 2017 was 7.3 billion dollars, and the $53 \%$ corresponded to the military market. However, according to the market structure, $84 \%$ corresponds to consumer drones, $15 \%$ to commercial drones and only $0.5 \%$ corresponds to military drones, due to the high costs of this type of drones.

It is expected that the cost of the components for the building of a drone will decrease between $7 \%$ and $27 \%$ by 2020 due to the intervention in the market of new commercial actors. Also, the drone market will grow and reach 9.5 billion dollars.

According to Gartner, 2.1 million drones were built in 2016. It was expected that in 2017 this number will reach 3 million, with an average annual growth of $34 \%$.

In the world, people have been actively working on regularizing the usage of drones in different situations $[2,3]$. Considering its continuously growing spectrum of use, securing the drones becomes a priority to reduce the risks related with their utilization. Different companies begin to offer insurance services to the drone owners. Nowadays, drones are even displacing satellites, and this trend is expected to continue growing. The emergence of millions of jobs related to the exploitation of drones in various aspects of human life is forecast.

The drones' development is conditioned by the future usage they will be given. According this, they will be limited in size, speed, etc. For example, for illegal actions such as robberies, violation of human rights (prohibited photographs), transportation of narcotics and illegal drugs a faster and discreet drone is required.

One of the areas where drones are developing more actively is the cargo transport [4]. The drones offer significant advantages over the classic transport such as elimination of traffic jams, lower environmental pollution, minimum delivery times and minimum takeoff and landing surfaces.

This article describes the process of planification, analysis, construction, building and economical evaluation of a drone in Ecuador.

\section{Materials and methods}

\subsection{Analysis of energy consumption by number of rotors}

The possible combinations and configurations of the rotors used to build a drone and the analysis of the energy consumption is displayed in Figure 1.

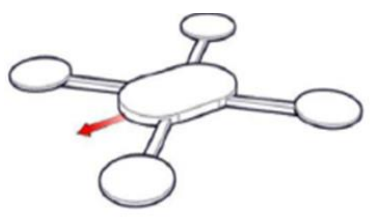

Four-rotor UAV

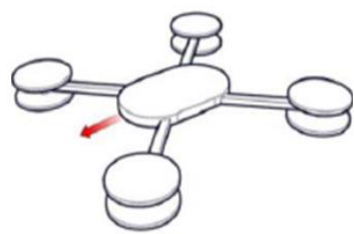

Eight-rotor UAV

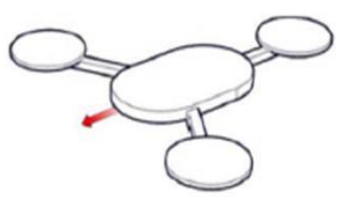

Three-rotor UAV

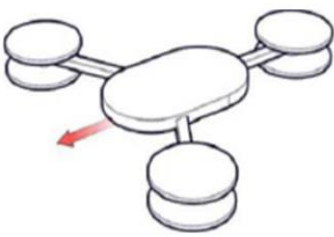

Six-rotor UAV
Fig.1. Unmanned Air Vehicle (UAV) Configuration

Dmitri Aleksandrov [5], describes and compares UAVs with different numbers of rotors, obtaining different parameters in terms of energy consumed by each rotor, rotor speed, energy that the rotor must

\footnotetext{
* Corresponding author: ffreire@ ute.edu.ec
} 
deliver, stationary flight time, etc. Table 1 shows the details of this study.

Table 1. Energy consumption according to the number of drone rotors

\begin{tabular}{|l|c|c|c|c|}
\hline \multicolumn{1}{|c|}{ Number of rotors } & $\mathbf{4}$ & $\mathbf{3}$ & $\mathbf{8}$ & $\mathbf{6}$ \\
\hline Mass (kg) & 1.4 & 1.32 & $\mathbf{1 . 7 2}$ & 1.56 \\
\hline $\begin{array}{l}\text { Force produced by each } \\
\text { rotor (or pair) (N) }\end{array}$ & 3.5 & 4.4 & $\mathbf{4 . 3}$ & 5.2 \\
\hline $\begin{array}{l}\text { Thrust force for each } \\
\text { rotor (or pair) Fh (N) }\end{array}$ & 0.7 & 0.88 & $\mathbf{0 . 8 6}$ & 1.04 \\
\hline Angle $\alpha$ (degrees) & 11.31 & 11.31 & $\mathbf{1 1 . 3 1}$ & 11.31 \\
\hline $\begin{array}{l}\text { Rotor speed (RPM), in } \\
\text { stationary flight }\end{array}$ & 5334 & 5967 & $\mathbf{4 6 5 6}$ & 5095 \\
\hline $\begin{array}{l}\text { Single motor power (W), } \\
\text { in stationary flight }\end{array}$ & 32.5 & 40.3 & $\mathbf{2 3 . 8}$ & 29.4 \\
\hline $\begin{array}{l}\text { Stationary flight time } \\
\text { (min) }\end{array}$ & 25.1 & 27 & $\mathbf{1 7 . 2}$ & 18.5 \\
\hline $\begin{array}{l}\text { Stationary flight time } \\
\text { with 1Kg load }\end{array}$ & 35.2 & 35.7 & $\mathbf{2 9 . 5}$ & 28.9 \\
\hline $\begin{array}{l}\text { Rotor speed (RPM), in } \\
\text { horizontal flight }\end{array}$ & 5385 & 6024 & $\mathbf{4 7 0 0}$ & 5142 \\
\hline $\begin{array}{l}\text { Power of a single motor } \\
\text { (W), in horizontal flight }\end{array}$ & 33.2 & 41.2 & $\mathbf{2 4 . 4}$ & 30 \\
\hline $\begin{array}{l}\text { Horizontal flight time } \\
\text { (min) }\end{array}$ & 24.5 & 26.4 & $\mathbf{1 6 . 7}$ & 18.1 \\
\hline $\begin{array}{l}\text { Horizontal flight time } \\
\text { with 1 kg load (min) }\end{array}$ & 34.4 & 34.9 & $\mathbf{2 8 . 8}$ & 28.2 \\
\hline
\end{tabular}

Table 1 shows that the three-rotor configuration provide the drone with greater efficiency in energy consumption. The difference between a three-rotor and a four-rotor drone configuration is only $1.5 \%$. However, the drones with four rotors offer enhanced maneuverability and stability compared to the three-rotor drones [6].

From the data provided above, it can be concluded that the coaxial octocopter has the best stability characteristics in comparison with other drones, especially regarding the lift of payload. Even though it consumes more energy, the eight-rotor drone is the most appropriate. For this reason, a drone with the "Coaxial Octocopter X8" configuration was selected for this project.

\subsection{Selection of the material for the drone}

For the project, aluminum, steel and carbon fiber were analyzed. The factors to be considered to select the material were:

-Resistance (fragile)

-Rigidity (flexible)

-Weight (heavy)

-Cost

Aluminum, steel and carbon fiber meet all the criteria mentioned above, but each one is unique in terms of strength, rigidity, weight and cost, as shown in the following Table 2 .
Table 2. Comparison of materials

\begin{tabular}{|l|l|l|l|}
\hline Characteristics & Steel & Aluminum & $\begin{array}{l}\text { Carbon } \\
\text { fiber }\end{array}$ \\
\hline Resistance to stress & High & High & Very high \\
\hline Fatigue resistance & High & High & Very high \\
\hline Overall thickness & Low & Low & Very low \\
\hline Own weight & High & Low & Low \\
\hline Corrosion & Yes & Yes & No \\
\hline Use & Difficult & Difficult & Easy \\
\hline Handling & Hard & Easy & Easy \\
\hline $\begin{array}{l}\text { Crossing between } \\
\text { elements }\end{array}$ & Hard & Hard & Easy \\
\hline Cost of materials & Low & Low & High* \\
\hline Cost of installation & High & High & Low \\
\hline
\end{tabular}

Steel has good qualities regarding strength, but its density is high, and it has corrosion problems. Steel's density is 3 times the density of the aluminum alloys. Aluminum has adequate strength; it is a material widely used in aeronautics. Aluminum has low density and is easy to handle. The strength of carbon fiber is superior to that of steel and aluminum. Carbon fiber offers a lower weight in the same proportion of surface and volume. However, the need to use of several layers of fabric in the areas of union and, above all, the need to homogenize it with resins and adhesives, end up almost equaling in weight with the aluminum.

In any case, although of equal weight, a carbon fiber piece will always be more solid than an aluminum piece. In addition, carbon fiber is resistant to corrosion, fire, chemical inertia and electrical conductivity [7]. Additionally, in the face of temperature variations, carbon fiber retains its shape. With these considerations, we concluded that the material suitable for the project is carbon fiber.

\subsection{Design and mechanical simulation of the drone}

The design of the drone structure was made using the SolidWorks, for which several designs were assayed to meet the demands of the project $[8,9]$.

During the study it was concluded that the drone should consist of three layers, two to settle the base of the engines, hold in the electronics and power supply and another layer to hold the payload

The studies were carried out applying forces of $50 \mathrm{~N}$ in the arms of the structure with different supports and with the three layers of solid material. Then, several assays were performed with different emptying of the layers of the drone. In this article the most important results are shown.

Figure 2 shows the emptying that allowed to minimize the weight of the first lid and obtain good tension, displacement and deformation results by the applied forces. The ends of the cover are carefully analyzed as they are the fastening points for the support tubes of the 8 drone engines. 
Tension forces (von Mises)

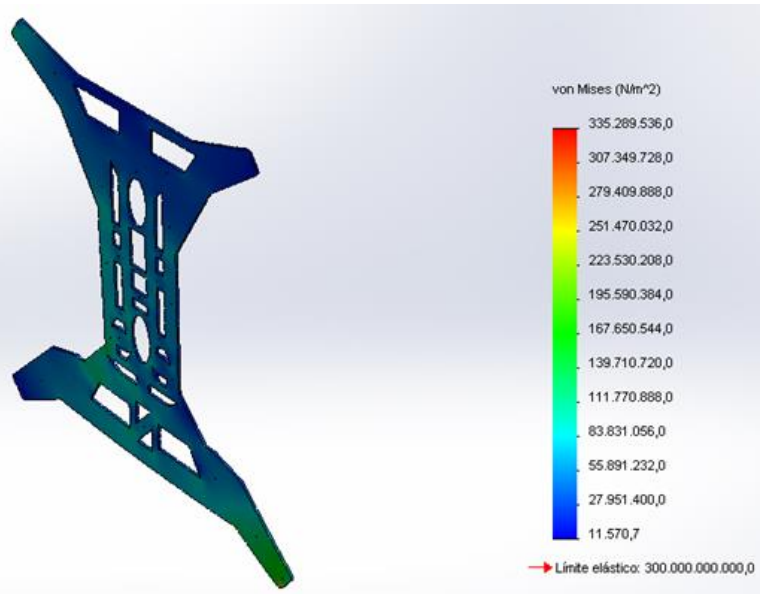

Unitary deformations (ESTRN)

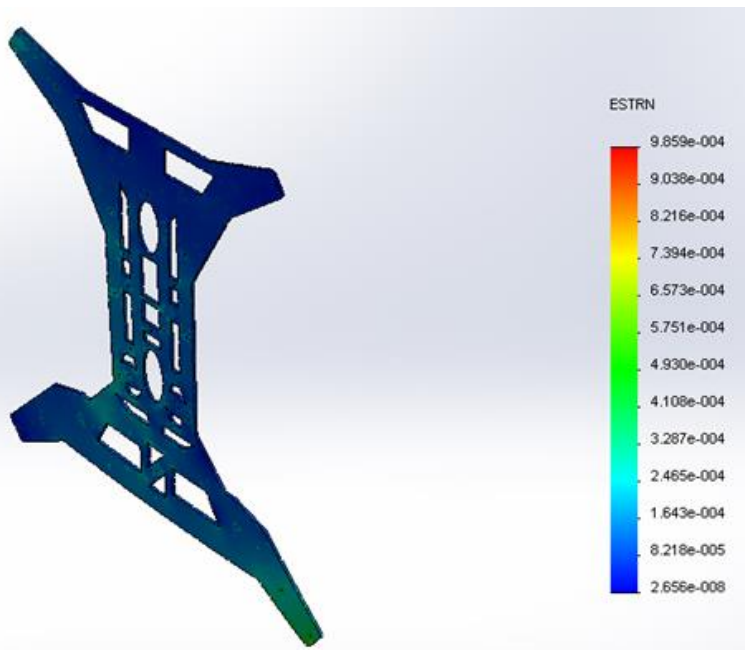

Fig.2. Lid 1 design

Figure 3 shows the design of the second lid, which has a different emptying compared with the Lid 1, as it will serve as a base for the electronic components of control of the drone. The best results were obtained with the forces applied at the ends.

Tension forces (von Mises)

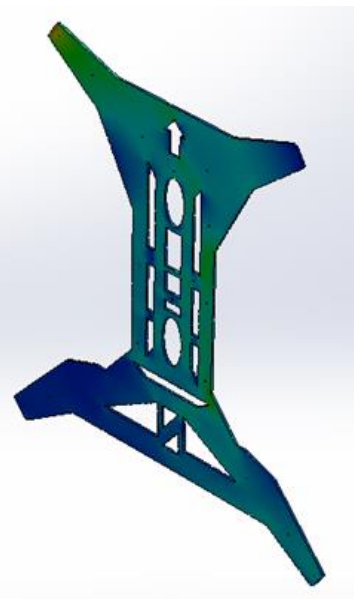

Unitary deformations (ESTRN)

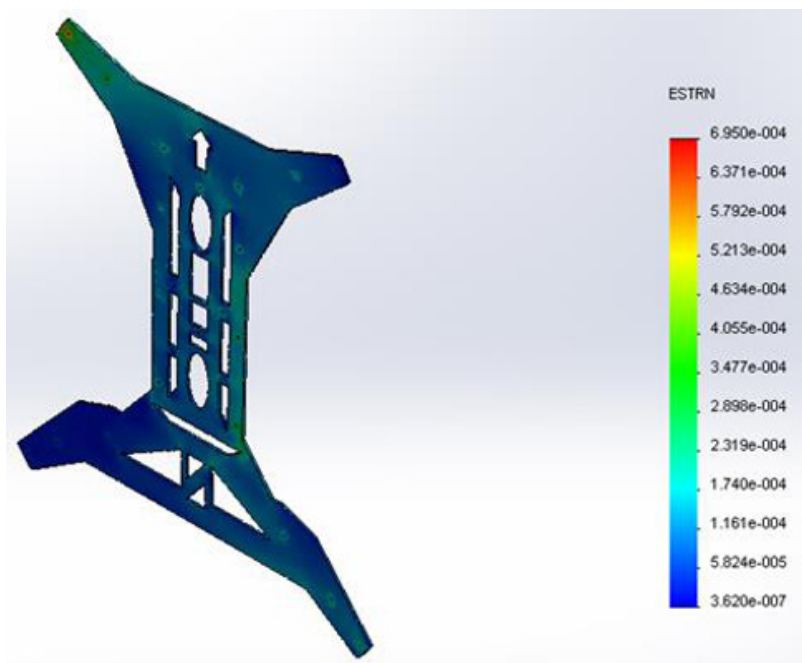

Fig. 3. Lid 2 design

Tension forces (von Mises)

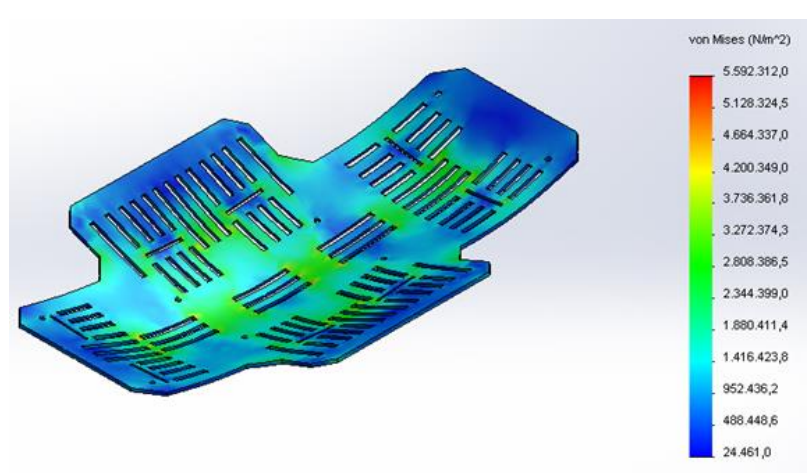

Displacement (URES)

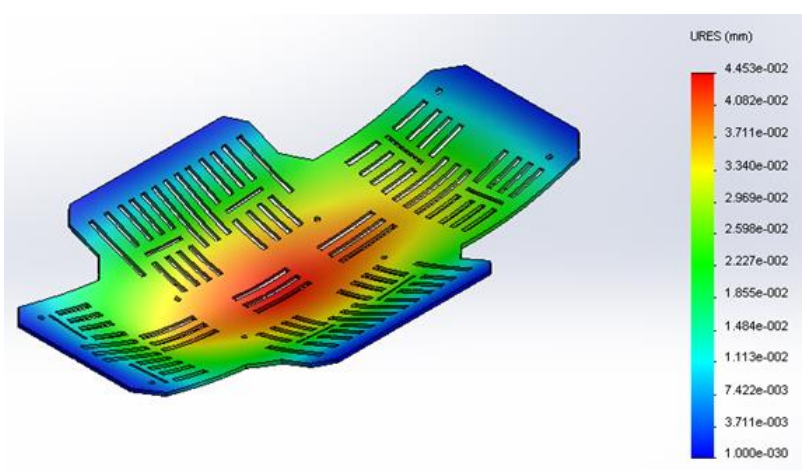

Fig. 4. Lid 3 design

The third lid (Fig. 5) is used to place the useful load of the drone with 4 points of subjection, the applied emptying allows to obtain the best results in terms of tension, displacement and deformation. The mass of the lid is $0.49 \mathrm{~kg}$, made with carbon fiber material, and a reaction force of $31.9 \mathrm{~N}$. 
Tension forces (von Mises)

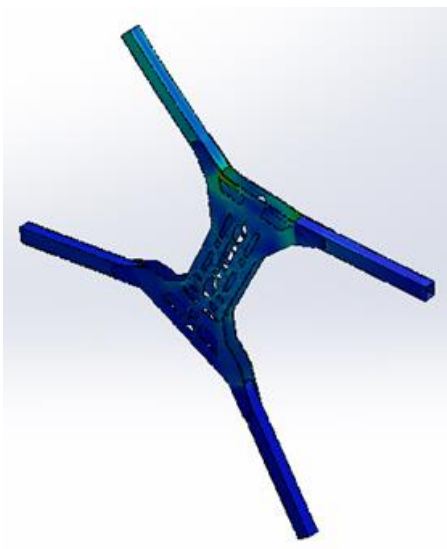

Displacement (URES)

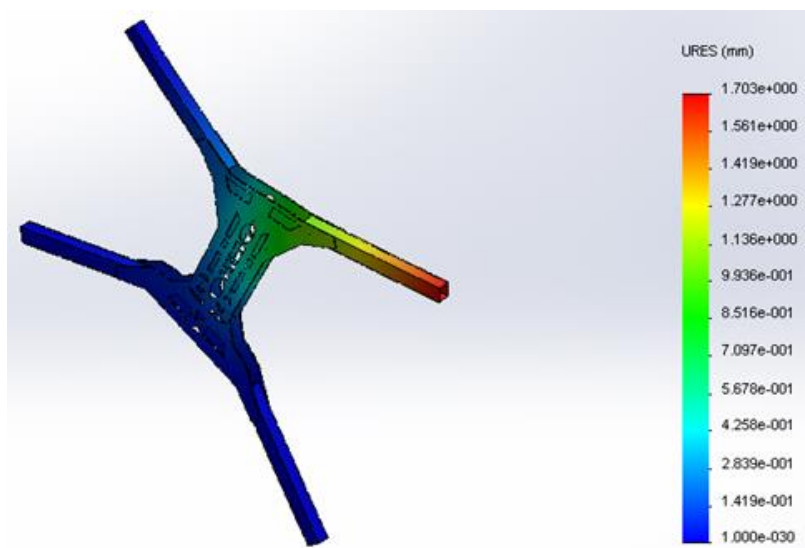

Fig. 5. Assembled drone

After the design stage, the drone was built taking into account all the requirements and the results of the analyzes and simulations of the different drone configurations. Thus, the final prototype met the quality and safety standards necessary for this type of projects.

\subsection{Power source selection}

For the analysis and selection of the battery type that allows to comply with the requirements of the project, the eCalc simulator was used. This simulator allows the determination of the type of batteries with an accuracy of $+/-15 \%$ knowing some characteristics of the drone, such as weight, dimensions, flight height, engine types and number, configuration. Table 3 shows the parameter used for the calculation of the energy needed for the system.

Table 3. Calculation of energy required for the system

\begin{tabular}{|c|c|c|}
\hline Category & Characteristic & Value \\
\hline \multirow[t]{7}{*}{ General } & Engine cooling & Excellent \\
\hline & Number of rotors & 8 (coaxial) \\
\hline & Model weight & $850 \mathrm{~g}(30 \mathrm{oz})$ \\
\hline & Frame size & $2000 \mathrm{~mm}$ (78.74 inch) \\
\hline & Fiel elevation & $2800 \mathrm{~m}$ ASL (9186 ft ASL) \\
\hline & Air temperature & $25^{\circ} \mathrm{C}\left(77^{\circ} \mathrm{F}\right)$ \\
\hline & Pressure (QNH) & $1013 \mathrm{hPa}(29.91 \mathrm{inHg})$ \\
\hline \multirow[t]{6}{*}{ Battery cell } & Type (Cont./max. C) - charge state & LiPo $22000 \mathrm{mAh}-15 / 25 \mathrm{C}-$ full \\
\hline & Configuration & $6 \mathrm{~S}, 2 \mathrm{P}$ \\
\hline & Cell capacity & $22000 \mathrm{mAh}(44000 \mathrm{mAh}$ total $)$ \\
\hline & Maximum discharge & $85 \%$ \\
\hline & Voltage & $3.7 \mathrm{~V}$ \\
\hline & Weight & $476 \mathrm{~g}(16.8 \mathrm{oz})$ \\
\hline \multirow[t]{3}{*}{ Controller } & Type & Max $50 \mathrm{~A}$ \\
\hline & Current & 50 A cont. (50 A max.) \\
\hline & Weight & $65 \mathrm{~g}(2.3 \mathrm{oz})$ \\
\hline \multirow[t]{5}{*}{ Motor } & Manufacturer - Type (Kv) & Tiger motor - U8-16² (100) \\
\hline & $\mathrm{KV}$ (w/o torque) & $100 \mathrm{rpm} / \mathrm{V}$ \\
\hline & No-load Current & $0.6 \mathrm{~A} @ 22.2 \mathrm{~V}$ \\
\hline & Limit (up to $15 \mathrm{~s}$ ) & $750 \mathrm{~W}$ \\
\hline & Weight & $240 \mathrm{~g}(8.5 \mathrm{oz})$ \\
\hline \multirow[t]{3}{*}{ Propeller } & Type - yoke twist & T-Motor $\mathrm{CF}-0^{\circ}$ \\
\hline & Diameter & 29 inch $(736.6 \mathrm{~mm})$ \\
\hline & Pitch & 9.9 inch $(251.5 \mathrm{~mm})$ \\
\hline Estimated max & $\begin{array}{r}\text { Hover flig } \\
\text { Thrust-weight }\end{array}$ & $\begin{array}{l}\text { Electric power } \\
\text { Specific thrust }\end{array}$ \\
\hline
\end{tabular}




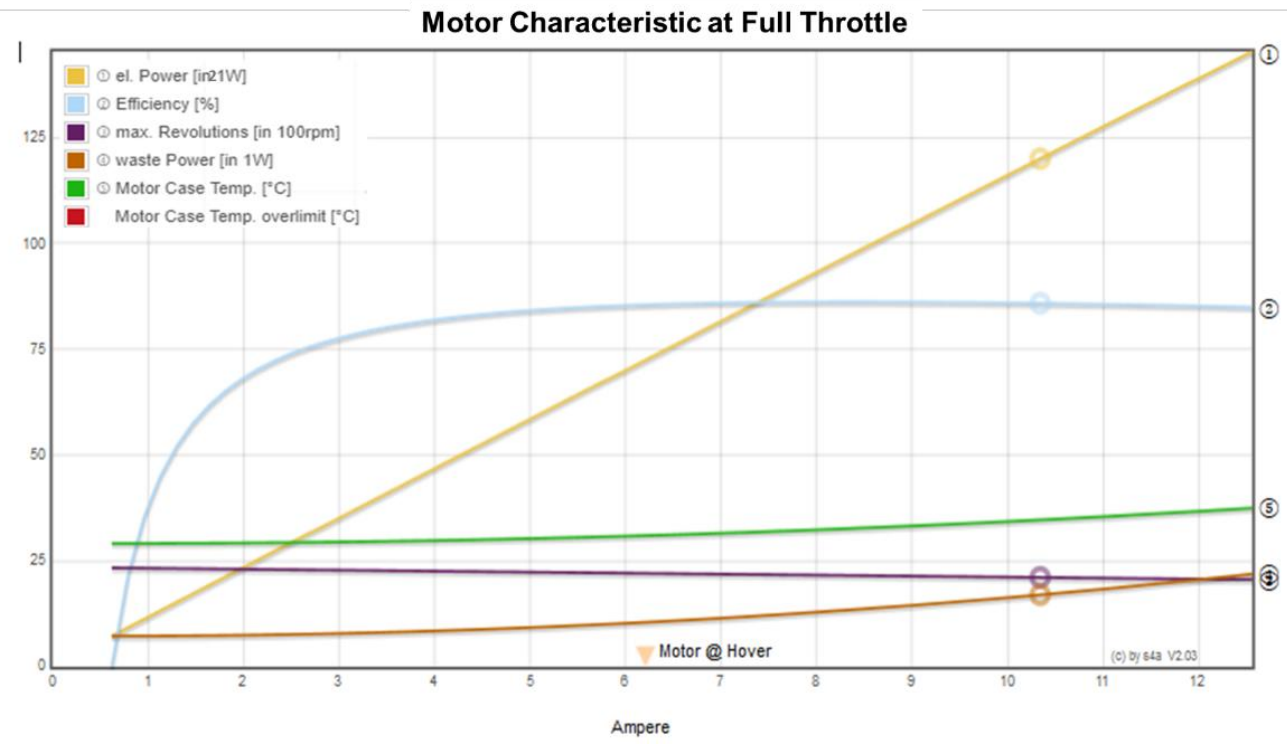

Fig. 6. Drone configuration for source selection

From the analysis of figure 6 , we concluded that the best option is to use two LiPo batteries of $22000 \mathrm{mAh}$ $15 / 25$, since these allow to reach the 45 minutes of autonomous flight with load, power and necessary thrusts, to fly at 2800 meters of height.

\subsection{Drone control system}

The hardware components were specially selected to work with ArduPilot, an Open Source autopilot board that uses an ATMega328 chip, and allows the connection of sensors, GPS and other. It also permits the control of the drone by radio, an automatic control following a previously established trajectory and flight through designated points [10]. ArduPilot supports the sending of telemetric information from the sensors on board to the control station, which can be a computer, telephone or tablet and records data in the memory aboard the drone.

Ardupilot has many advantages over DJI NAZA, Wookoong-M, ZeroUAV (YS-X4, YS-X6), Mikrocopter, Hovefly Pro, and uThree. Ardupilot has a low price, full autopilot, supports the possibility to place 166 flight points, edit the route in flight, permit a remote configuration of the parameters, supports GEO-FENCE, has an open data transmission protocol, supports configurations for tricopters, quadricopters, hexacopters, octacopters, Y6, X8, helicopters, airplanes, cars and ships, supports flight simulation with Mission Planner.

The technical characteristics of the components of the drone to meet the objective are presented in Table 4.

Table 4. Technical specifications of the drone components.

\begin{tabular}{|l|c|l|c|}
\hline Component & \multicolumn{2}{|c|}{ Description } & Amount \\
\hline & & $\mathrm{U} 8-10$ & \\
& & $\mathrm{KV}: 170 \mathrm{rpm} / \mathrm{v}$ & \\
no load current & \\
Engines & Characteristics & $\begin{array}{l}: 1.1 \mathrm{a} / 22.2 \mathrm{v} \\
\text { max watts/time }\end{array}$ & 8 \\
& & $: 750 \mathrm{w} / 180 \mathrm{~s}$ & \\
& & max amps/time & \\
& &
\end{tabular}

\begin{tabular}{|c|c|c|c|}
\hline \multirow[t]{2}{*}{ Component } & \multicolumn{2}{|c|}{ Description } & Amount \\
\hline & & $\begin{array}{l}: 24 \mathrm{a} / 180 \mathrm{~s} \\
\text { resistance ohm } \\
: 186 \mathrm{~m} \Omega \\
\text { case } \\
\text { height/length : } \\
86.8 \mathrm{c} 26.5 \mathrm{~mm} \\
\text { weight in } \\
\text { grams }: 240 \mathrm{~g}\end{array}$ & \\
\hline Propellers & Characteristics & $\begin{array}{l}\text { 29x9.5prop } \\
104.9 \mathrm{~g} / \text { sheet } \\
\text { Sandwich-like } \\
\text { construction }\end{array}$ & 8 \\
\hline \multicolumn{2}{|c|}{ Flight controller } & $45 \mathrm{~A}, 8 \mathrm{~S}$ & 1 \\
\hline \multicolumn{2}{|c|}{ Carbon fiber tubes } & $\begin{array}{l}\text { Rectangles } \\
\text { 30x40mm, } \\
\text { thickness: } \\
\text { 2mm, 380mm } \\
\text { long }\end{array}$ & 4 \\
\hline Plates & & $\begin{array}{l}\text { 600x600mm, } \\
\text { thickness: } \\
3 \mathrm{~mm} \\
250 \times 300, \\
\text { thickness: } 1 \mathrm{~mm}\end{array}$ & $\begin{array}{l}1 \\
2\end{array}$ \\
\hline \multicolumn{2}{|l|}{ Landing gear } & $\begin{array}{l}\text { double bar, } \\
\text { carbon fiber } \\
16 \times 15 \times 500 \mathrm{~mm} \\
\text { base, carbon } \\
\text { fiber } \\
\text { 10x9x400mm }\end{array}$ & 2 \\
\hline \multicolumn{2}{|c|}{ Drone fasteners } & $\begin{array}{l}\text { Thickness: } \\
\text { 3mm, } \\
\text { aluminum }\end{array}$ & 8 \\
\hline \multicolumn{2}{|c|}{ Three-floor structure } & $\begin{array}{l}\text { First layer: } \\
\text { GPS } \\
\text { Second layer: } \\
\text { arms of the } \\
\text { Drone } \\
\text { Third layer: } \\
\text { holds landing } \\
\text { gear and } \\
\text { electronic } \\
\text { section }\end{array}$ & \\
\hline
\end{tabular}




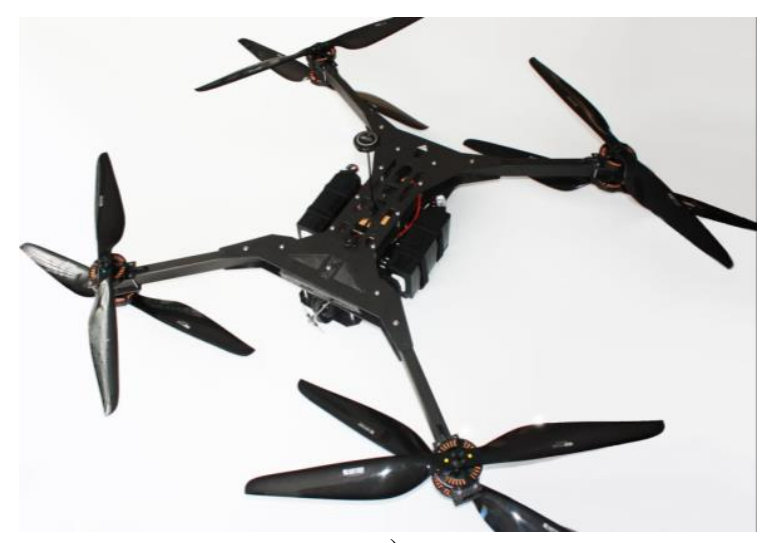

a)

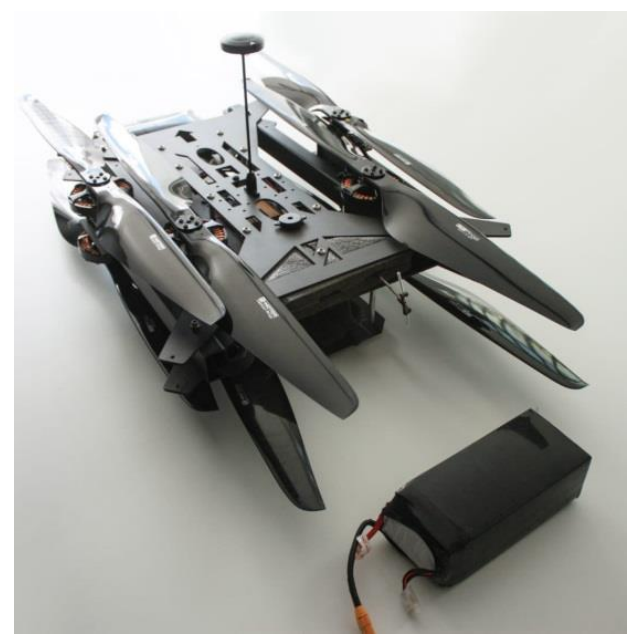

b)

Fig. 7. View of the drone a) deployed, b) retracted

\subsection{Analysis of national added value}

The drone is made of 147 elements (Fig. 7), divided into three groups according to the importance of each of them within the project. These categories are: parts/pieces that represent $66 \%$ of the drone, materials - $28 \%$ and software $-6 \%$ of the drone. An economic analysis was carried out according to the origin of each group, whether Ecuadorian or foreign. Additionally, an economic projection to 5 years was performed, if there are performed investments and research in this area. The results are displayed in Figure 8 and 9.

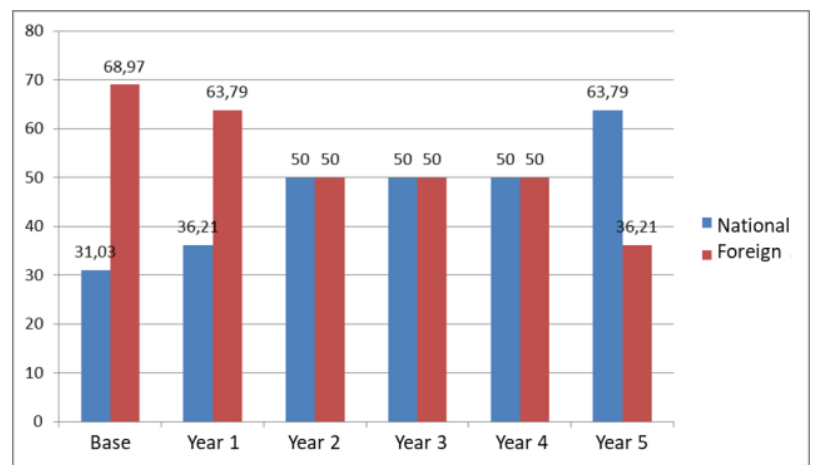

Fig. 8. Distribution by components at 5 years

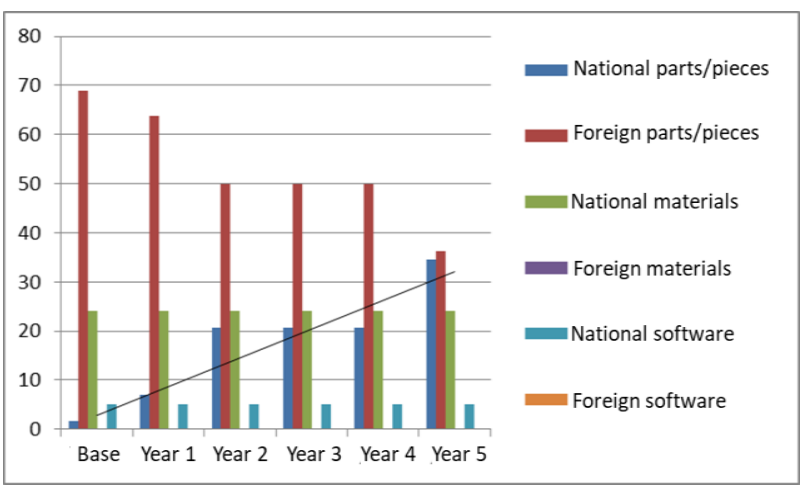

Fig. 9. Distribution by group at 5 years

\section{Conclusions}

In Figure 9, the year of acquisition of the drone components, the foreign component represents $68.97 \%$, and it decreases to $36.21 \%$ in the fifth year. The national (Ecuadorian) component at the beginning represents $31.03 \%$ and at the fifth year it represents $63.79 \%$, being the national parts/pieces component that grows more according to the trend. It is shown that this type of project is viable at a medium term and will create jobs and added value to the country. All of this without considering the increase of jobs in the provision of services related to the manufacture and incorporation of this technology in the various fields of production, defense and research in Ecuador.

\section{References}

1. J'son \& Partners Consulting, Drone market in Russia and in the world, (2018)

2. C. Zhang, J.M. Kovacs, PA, 13, 693-712 (2012)

3. N.D. Bublik, D.V. Chuvilin, G.A. Shafikov, ESJ, 2(10), (2018)

4. A.M. Almeshal, M.R. Alenezi, A.K. Alshatti, Information, 11(9), 442 (2020)

5. D. Aleksandrov, I. Penkov, Parnu (2012)

6. F. Sarghini, A. De Vivo, ChET, 58, 625-630 (2017)

7. M. Budinger, A. Reysset, A. Ochotorena, S. Delbecq, AST, 98, (2020)

8. H. Yang, Y. Lee, SY. Jeon, et al, ISR10, 79-93 (2017)

9. T. Kilby, .B. Kilby, Make: Getting started with drones, Makermedia, (2016)

10. K. Gabuev, V. Gongalo, N. Kucherenko, A. Shipko, ATIB-P, 10, (2018) 